\title{
Management of relapse in acute promyelocytic leukemia treated with upfront
}

\section{Arsenic trioxide based regimens}

Fouzia NA, Vibhor Sharma, Anu Korula, Anup Devasia, Uday Kulkarni, YasirJeelani, Thenmozhi Mani, Jeyaseelan Lakshmanan, Alok Srivastava, Aby Abraham, Poonkuzhali Balasubramanian, Biju George, Vikram Mathews. Department of Haematology, Christian Medical College, Vellore, India

\section{INTRODUCTION}

The standard of care for patients with acute promyelocytic leukemia (APL) relapsing after frontline treatment with Arsenic trioxide (ATO) based regimens remains to be defined. Available data on response and survival outcomes in patients who had received ATO as part of upfront therapy suggests that there is a high incidence of resistance to ATO and ATRA resulting in inferior response and inferior survival than seen in patients who has not received ATO as part of upfront therapy ${ }^{1}$. We present our experience on management of relapse in APL patients treated with frontline ATO based therapy.

\section{PATIENTS AND METHODS}

Data on all consecutive patients with relapsed APL diagnosed and treated in the Depatment of Haematology, Christian Medical College, Vellore, from January, 1998-December, 2015 were included in this retrospective analysis.

\section{RESULTS}

$104(29 \%)$ of the total 358 APL patients diagnosed during the study period had relapsed. Out of these 73 (70\%) patients received upfront ATO based therapy. $6 / 73$ refused treatment; the remaining 67 (91.8\%) were included in the analysis

\begin{tabular}{|lc|}
\hline \multicolumn{2}{|c|}{ Table : 1 Baseline characteristics of patients (n=67) } \\
\hline \multicolumn{1}{|c|}{ Variable } & N (\%)/Median (Range) \\
\hline Age (in years) & $28(4-54)$ \\
\hline Gender & $44(65.7)$ \\
Male & $23(34.3)$ \\
Female & $19.6(5.9-128.4)$ \\
\hline Time to relapse from diagnosis (mths) & \\
\hline Sites of relapse & $1(1.5)$ \\
Isolated molecular & $6(9.0)$ \\
Isolated CNS* & $13(19.4)$ \\
Marrow+CNS & $47(70.1)$ \\
Isolated Marrow & \\
\hline Re-induction regimens at relapse & $9(13.4)$ \\
ATO+Anthra/ATO +Bortezomib & $10(14.9)$ \\
ATO+ATRA & $26(38.8)$ \\
ATO+ATRA+Anthra** & $22(32.8)$ \\
ATO+ATRA+Anthra+Bortezomib & \\
\hline Response to re-induction at relapse & $63(94.0)$ \\
Molecular remission & $1(1.5)$ \\
Discontinued treatment & $3(4.5)$ \\
Expired & \\
\hline Post re-induction Trt at CR2 ( $n=63)$ & $35(55.6)$ \\
Auto-SCT*** & $28(44.4)$ \\
\hline ATO based maintenance chemotherapy & $5.8(1.8-32.2)$ \\
\hline Time to auto-SCT from relapse (mths) &
\end{tabular}

*Central Nervous System "*Anthracycline "**autologous stem cell transplantation

\begin{tabular}{|c|c|c|c|c|}
\hline \multirow[b]{2}{*}{ Variables } & \multirow{2}{*}{$\begin{array}{l}\text { Hazard } \\
\text { Ratio }\end{array}$} & \multicolumn{2}{|c|}{$95 \% \mathrm{Cl}$ for $\operatorname{Exp}(\mathrm{B})$} & \multirow[t]{2}{*}{ P value } \\
\hline & & Lower & Upper & \\
\hline \multicolumn{5}{|l|}{ Post Relapse Treatment } \\
\hline AutologousSCT & 1.00 & \multirow{2}{*}{1.988} & \multirow{2}{*}{28.873} & \multirow{2}{*}{0.003} \\
\hline ATO based Chemotherapy & 7.576 & & & \\
\hline Duration of CR1 & 0.999 & 0.998 & 1.000 & 0.143 \\
\hline Total WBC at Relapse & 1.017 & 0.992 & 1.042 & 0.187 \\
\hline Age & 1.005 & 0.959 & 1.053 & 0.832 \\
\hline REFERENCES & & & & \\
\hline
\end{tabular}
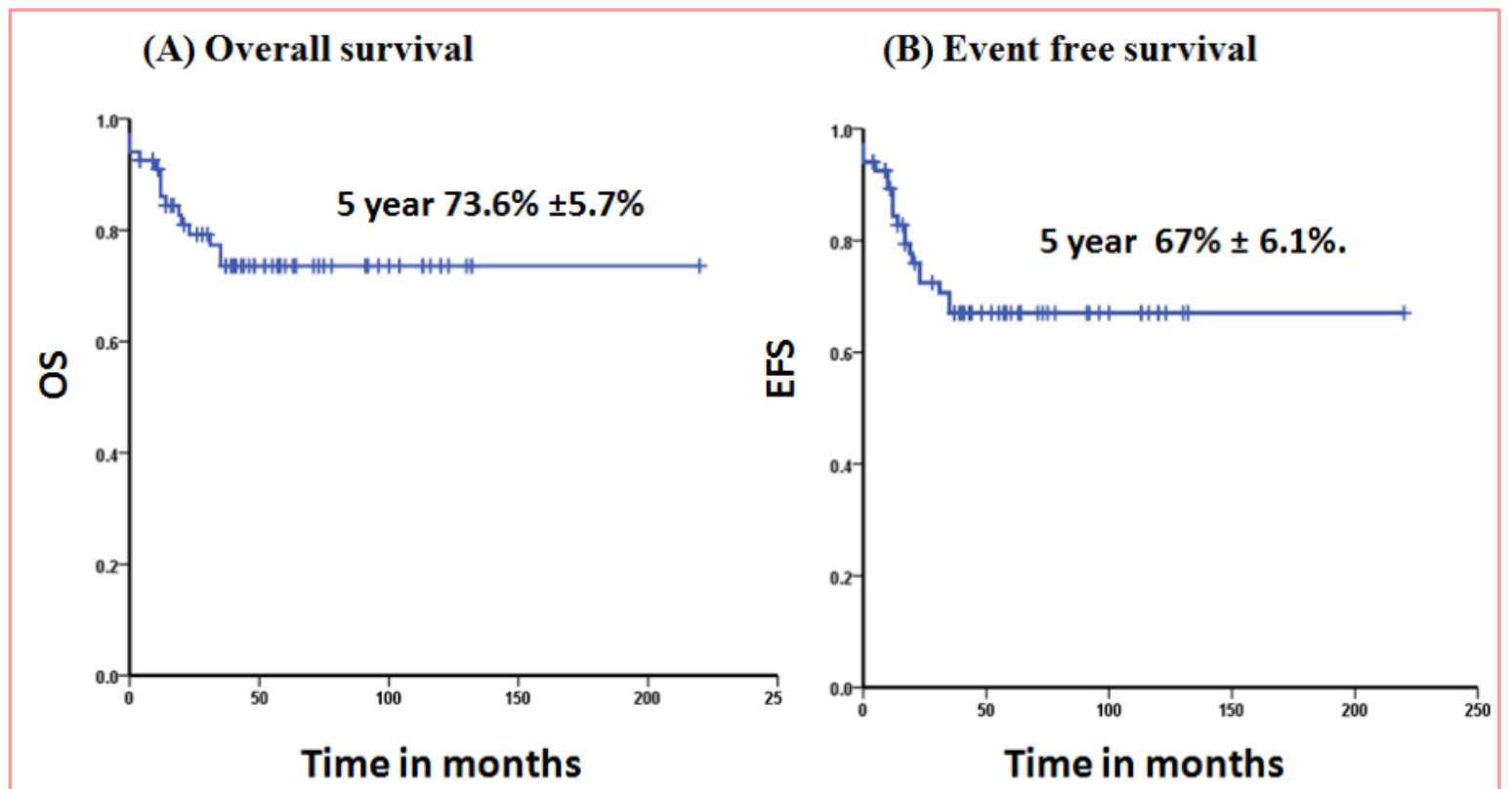

Fig 1: Kaphe Meier estimate of survival of relapse APL patients treated with upfront ATO based regimens (A) Overall survival (B) Event free survival
belat

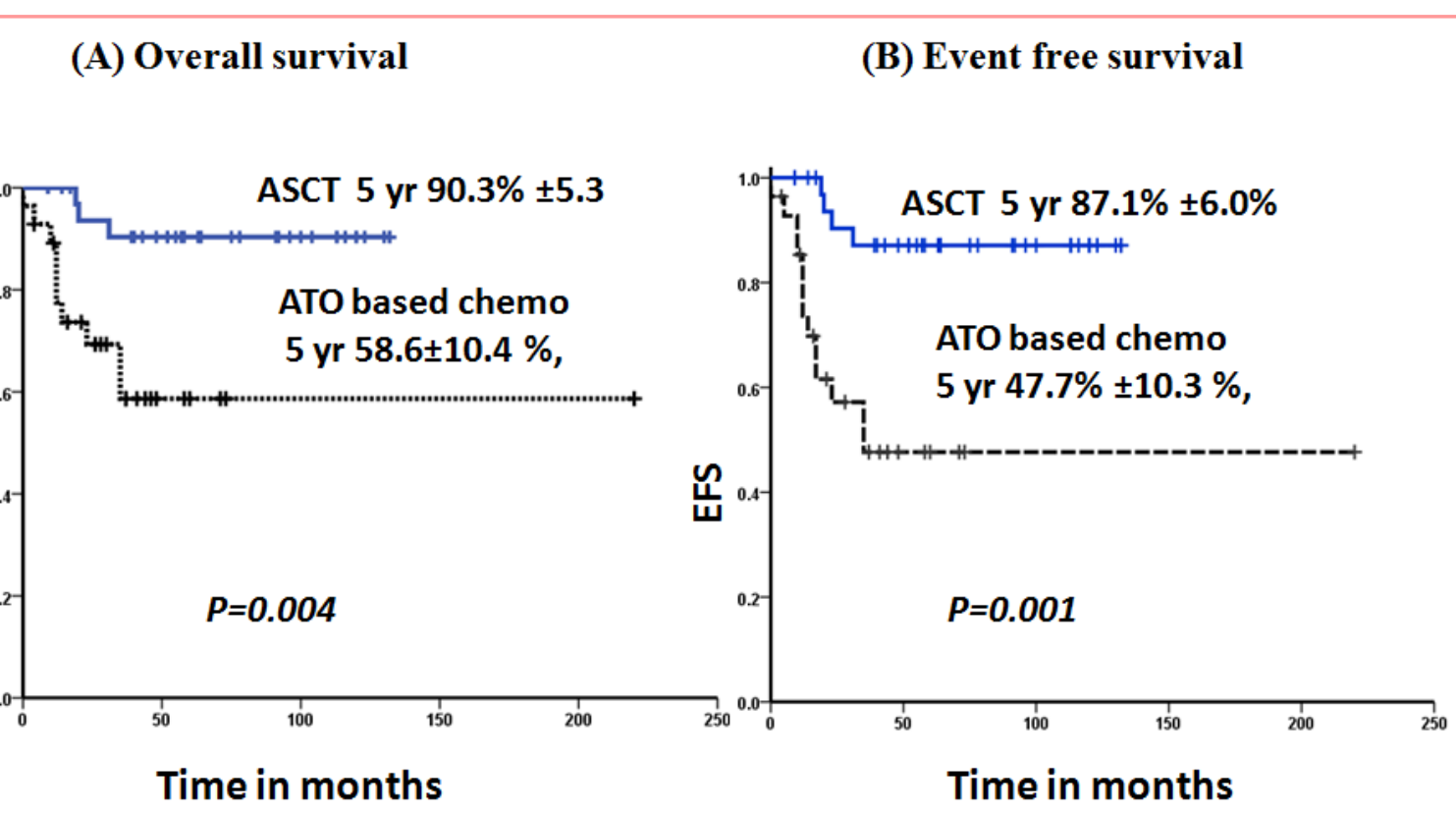

Fig 1: Kaplan - Meier estimate of survival of relapse APL patients treated with upfront ATO based regimens and received autologous stem cell transph chemotherapy in CR2 (A) Overall survival (B) Event free survival

\section{CONCLUSIONS}

Remission induction with ATO based regimens followed by an autologous SCT in patients with relapsed APL who were treated with frontline ATO based regimens is associated with excellent long term survival and should be considered the standard of care even in this setting. 